\title{
Refining Process, Expanding Practice: Public Interest Design Fieldnotes from the South
}

\author{
EMILIE TAYLOR WELTY
}

Tulane University

\begin{abstract}
University-based Community Design Centers have seen a resurgence in recent decades, and current inequities and social movements have given greater urgency to questions of who can access design and how. This paper outlines lessons learned over 12 years in the Albert and Tina Small Center for Collaborative Design's approach to educating citizen-architects, rethinking design processes, and executing projects with a deep commitment to engagement, place and design excellence. We use the design process as a powerful coalition building tool, a way to challenge traditional power dynamics, and are able to prove the value of design excellence in our city and shift conventions around who architects serve, what they work on, and why design matters. What follows are a few strategies for creating a thoughtful project selection process, building trust and capacity within project teams, and rethinking the education of designers towards more collaborative and inclusive processes.
\end{abstract}

\section{INTRODUCTION}

In this social and political moment in time, the United States is teaming with very public contradictions, factions, passions, and old ghosts that are causing people to take to the streets. Scientists, Feminists, Black Lives Matter supporters, racists, fringe groups, and others have exercised their first amendment rights to protest in public space. Increasingly in the classroom our design students have been turning to us educators to understand the current unrest and the place of architecture, and architects, within this context. What role has design played in creating and perpetuating an unjust society? What can we do to shape a better future?, how can Architects be a better citizens?, and how can we work towards a more equitable ${ }^{1}$ society as individuals in this overwhelmingly large and complex system?

While these questions feel fresh and pressing in 2017, there was a similar urgency in the work of the first wave of community design centers in the 1960's. Then community design centers were launched at a time of social upheaval in civil rights efforts, the anti-Vietnam war movement, the rise of women's liberation ${ }^{2}$ and as a way to counter a crisis in professional competence ${ }^{3}$. The second wave of community design centers and programs started in the 1990's and since the year 2000 the ACSA reports a steep increase in the number of community design centers in North America, from just under 70 to "over 200 active organizations, covering everexpanding geographic, disciplinary, and strategic territories ${ }^{4 \prime}$.
Today Public Interest Design (PID) is the term used by many contemporary community design centers and allied practitioners to describe their work. Working at the intersection of design and social justice these firms and non-profits see their work as expanding practice instead of setting up alternatives to practice ${ }^{5}$. Many of today's PID practices trace their ideological roots to the community design work of the 60's and 70's which was described by Mary C. Comerio in a 1984 article:

"Community design is based on a recognition that professional technical knowledge is often inadequate in the resolution of societal problems, and it represents the addition of a moral and political content to professional practice. In particular, it grew from the belief that all citizens had a right to be represented in decisions about the environment, and that planning would benefit from the maximum public input."

Traditional Architectural practices rarely have the time and money to address these professional-existential questions or explore different design processes and structures ${ }^{6}$. As a result, Architects most often serve the people and institutions with means, reinforcing the social and economic structures that have shaped the inequities of today, while everyday citizens without means are excluded from the design process and therefore excluded from shaping the built environment.

In creating a design center in 2005, the Tulane School of Architecture merged a desire to harness the creative energies of faculty and students for positive impacts in our city with a budding design/build program inspired by the work of our regional neighbor Rural Studio. Rural Studio provided an enviable mix of hands-on-education, real world outcomes, material innovation, and a commitment to place in a way that questions the role of the Architect and the process of design education? ${ }^{7}$. Our university-based design center was officially launched in the post-Katrina city rebuilding context, forcing us to grapple with what Mockbee called the ethical responsibilities of citizen-architects for over 12 years now. And while the moral and political content of design practice and our subversive role as educators contain questions we should have been asking all along, particularly in a city like New Orleans full of inequity and 'wicked problems's , sometimes it takes a disaster to expose underlying structural inequities and force a collective reflection. This paper outlines those lessons learned in our design center's approach to educating citizen-architects, rethinking design processes, and executing projects with a deep commitment to engagement, access, place, and design excellence. 


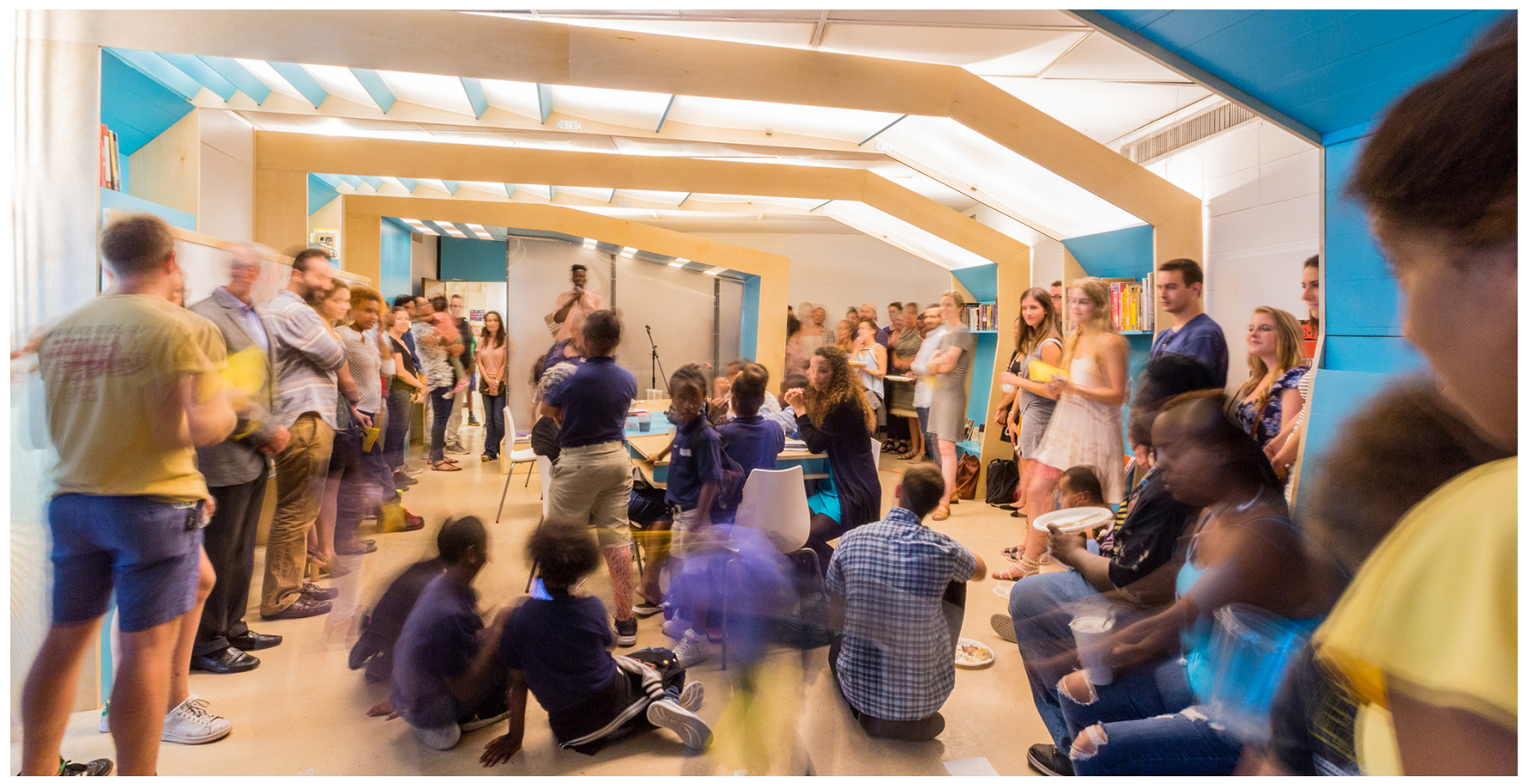

Figure 1: Big Class Writers' Room Event. Spring 2017 design/build collaboration with a non-profit youth writing program

\section{CONTEXT: THE ALBERT AND TINA SMALL CENTER FOR COLLABORATIVE DESIGN}

As the community design center of the Tulane School of Architecture, the Small Center brings together creative makers and doers, working towards a better city. We advance community-driven ideas through collaboration, design education, and scrappy problem-solving. We use the design process as a powerful coalition building tool creating space for more voices in the design process; and our role in many projects extends beyond architecture to diplomacy, education, and facilitation. Through this process we are also able to prove the value of design excellence in our city and shift conventions (both in perception, and reality) around who architects serve, what

they work on, and why design matters. Our work is situated within a broader body of Public Interest Design work that is concerned with bringing design services to traditionally under-served communities and investigating more thoroughly how design can address social, economic, and environmental issues ${ }^{9}$.

Founded in 2005 as the Tulane City Center, in the past 12 years we have completed 98 projects with 82 community partners and over 500 students. Our work has helped local nonprofits and under-served communities leverage millions of dollars to build the capacity and infrastructure needed to support their missions. Embedded in these numbers is a constant effort to perfect our systems of operating, to question our assumptions and processes, and create a better education for our students and project outcomes for our partner organizations. What follows are a few lessons learned and ways we currently operate to craft a thoughtful project selection process, engage stakeholders in the design process, question underlying power dynamics in that process, and rethink the role of designers in shaping our built space.

\section{PROJECT SELECTION}

Our primary project intake system is an annual juried Request for Proposals (RFP) that we hold each spring. Through this RFP process we are able to understand the needs, ideas, and opportunities identified by community groups and non-profit organizations, rather than imposing our ideas of what the "community" needs ${ }^{10}$. The application is intentionally brief, a maximum of 3 pages, and designed to encourage entries. Beyond web based outreach we distribute the RFP through posters, fliers, and word of mouth, acknowledging that many in our community lack internet access. We hold an information session outlining the process and our abilities, and we offer applicants assistance in reviewing draft proposals before the submission date.

The process of selection involves convening a jury to discuss what we should be doing and why in the upcoming year and allows us to control our workload for the academic year. Each jury is a combination of community members, past project partners, students, and faculty members who review and rank proposals. A typical cycle sees 20-30 entries and the jury has a long thoughtful conversation before voting on the projects. Our voting matrix includes the perceived NEED for the project (its potential impact on challenging systems and 


\section{RFP PROJECT SUMMARY \& SCORE CARD}

Our emphasis on selecting projects is to seek opportunities to partner which foreground equitable approaches to addressing racial, gender and class disparities.

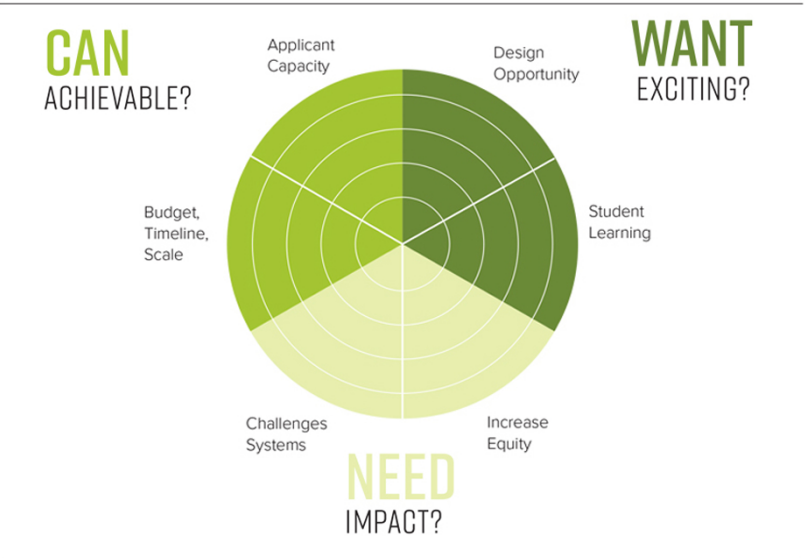

JUROR NOTES:

Figure 2: RFP Jury Process, Scorecard (left)

increasing equity), WANT for the project (does it provide and exciting design and education opportunity for our students?), and ABILITY to create a successful project (both in our ability to execute a project, and our partner's ability to maintain the built project or advance a visioning project). In addition to grounding our yearly project slate in actual needs of our partners and in our abilities, this RFP process is a first step in building trust with our stakeholders.

\section{PROJECT KICKOFF}

[Once a project is selected we have a few preparatory meetings with the partner organization's staff before design students join the team and the design process begins. These pre-design meetings begin with an initial set of questions that we ask with our partner and answer together:

- What is the primary thing we are trying to do?

- How will we measure this project's success?

-Who are the stakeholders in this project, and what are the most effective methods of engagement?

- How can we build capacity within our community?

- What are the student learning objectives?

- Are there readings the partner organization would recommend to frame the design investigation?

- How are we educating the public and expanding knowledge about the issues for New Orleans citizens? - At the project's conclusion, how will we celebrate?

Answering these questions with our partner organization allows us to set expectations, articulate the project scope and goals, frame the design exercise for the students, and convene a stronger coalition of project advocates and implementers. What results from the process of answering

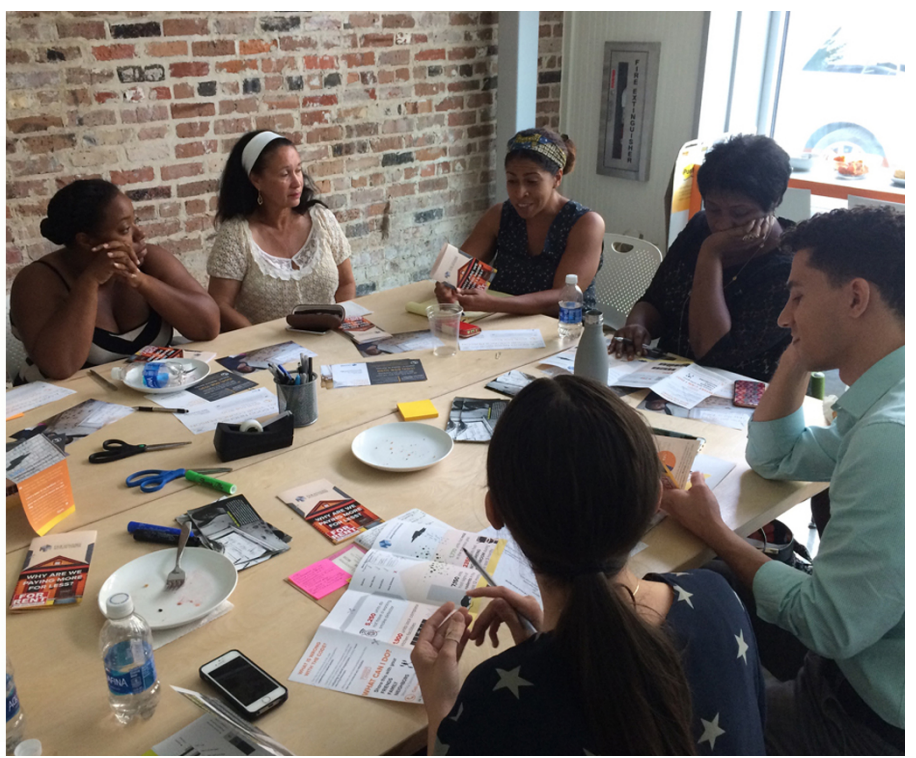

these initial questions is a robust discussion about how to engage, who to engage, nuances of who is represented, who represents, and the history of everyone's interrelationships.

At each step in the pre-design and design process we are questioning the power dynamics and working to subvert them ${ }^{11}$. At the beginning of each project we hold a 'teach in' where representatives of the partner organization teach our design team about the issues they are working on. In doing so our partners are positioned as the experts in their subject who are informing our design students on the substance and nuances of their work. For example, when working with an affordable housing advocacy organization the teach in included a history of Red-lining and discriminatory policies that have contributed to the current housing crisis, information which was surprisingly new for our 4 th and 5 th year design students.

\section{PROJECT PROPOSITION AND REVISION}

As part of a School of Architecture with a commitment to design excellence our design work is rooted in the rigor and iterative process of proposition, revision, and juried reviews. However, we've seen clear shortcomings in the typical architecture school design review structure in engaging and collecting feedback from stakeholders. We are constantly revising structures for engagement and design critique that will yield constructive input and the most meaningful design solutions ${ }^{12}$.

Our project stakeholders are typically not designers and many of them withdraw to silence when in a room with vocal design reviewers aiming their critical comments dense with design specific language (archi-speak) at students. In an effort to change the pace, power dynamics, visual legibility ${ }^{13}$ and constructive potential of reviews our continual review format experiments have led us to a few conclusions that help structure our community reviews: 


\section{BIG CLASS WRITERS ROOM PROJECT TIMELINE}

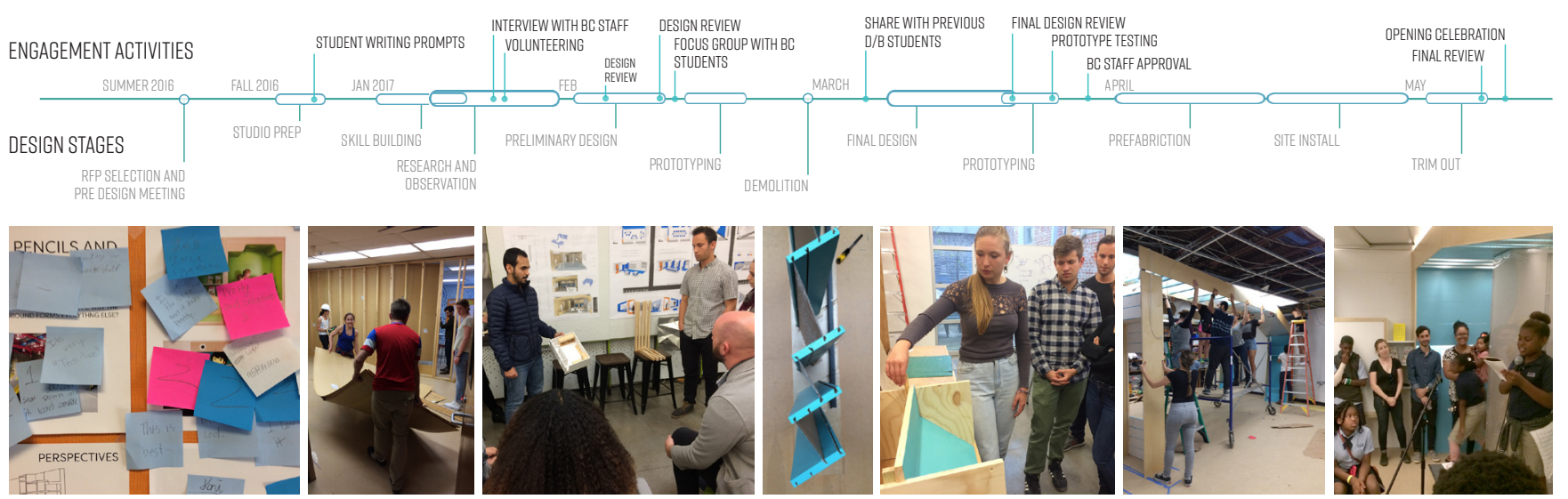

Figure 3: Timeline for a one-semester project outlining the overlay of engagement activities and design stages

$>$ Speak the language of your audience. Plans, Sections, and Elevations are helpful for design and fabrication but are less helpful for non-designers and their understanding of the proposal. Renderings, concept sketches, physical models, and detail mock-ups are more immediately understandable and approachable for non-designers. The same consideration goes into the language used in presenting.

$>$ Where you meet is important. Going to the stakeholders whether that's in a senior center or a park will make sessions easier to attend, put stakeholders more at ease, and increase the chances of candid conversation.

$>$ Keep moving. Active feedback whether that involves testing mock-ups, sharing physical models, post-it-note feedback, or small team conversations over grilled food are the most effective ways to get stakeholders to open up.

> Ask follow-up questions. Some collaborators, especially kids, can be harsh one word critics. We always coach our students in follow-up questions to understand why a design is considered 'bad', 'cool' or 'ugly'. Questions that get people to expand on qualities of space or materials, memories, and desires are the aim.

$>$ Invite others. We use reviews as a chance to build capacity in our partner organization and expand the project's networks and advocates. Reviews are an opportunity to reach past the staff of our partner organization and include their constituents and stakeholders as well as potential funders and project allies identified in the kickoff question session. This process of broader inclusion builds a network of people invested in the project's success.

\section{RETHINKING EDUCATION}

"Architects are by nature and pursuit leaders and teachers. If architecture is going to inspire community, or stimulate the status quo in making responsible environmental and social structural changes now and in the future, it will take what I call the 'subversive leadership' of academicians and practitioners to remind the student of architecture that theory and practice are not only interwoven with one's culture but with the responsibility of shaping the environment, of breaking up social complacency, and challenging the power of the status quo." -Samuel Mockbee ${ }^{14}$

As educators in a university-based design center our primary role is to educate young designers and also cultivate in them the ability to question existing systems and structures to be proactive agents of change in their communities. Yet as a community design center with a facility off campus we also bring others, non-designers, into the conversation and educate citizens and students alike by providing a venue for events, exhibits, and dialogue. Each month we host a 'Red Beans Roundtable' an event where we provide dinner and a broad audience of students and members of the New Orleans community participate in curated conversations about social justice and the built environment. These events and projects educate citizens about design and teach designers to be better citizens and provide an opportunity dispel a few myths in design education.

$>$ Design is collaborative, not about a mythical lone hero

Infected by pop-culture icons such as Frank Lloyd Wright or Frank Gehry or by case study assignments involving design greats like Louis Kahn or Le Corbusier, many beginning design students think of Architects as lone artistic geniuses. Design in our center is framed as a process of collaboration ${ }^{15}$, with other designers and technical consultants, as well as with our partner organizations and their constituents ${ }^{16}$. Design is about creative problem solving with others, an idea that is often difficult 


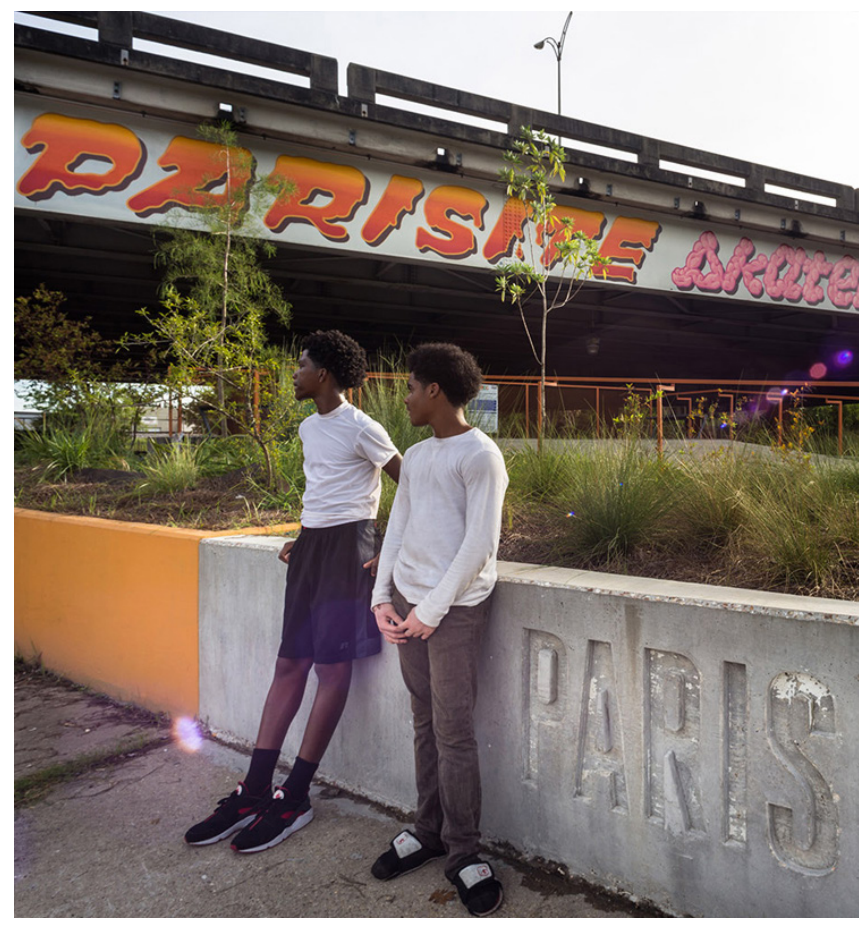

Figure 4: Parisite Skatepark: a collaboration which established a working relationship with city agenecies, state agencies, and site partners. The inital capacity building within an organization of skaters, Transitional Spaces, happened through a design/build project process and led to subsequent site development spearheaded by the Transitional Spaces team.

for our students to adjust to after 3-4 years of being the sole author of studio based design solutions. This uncomfortable struggle of collaboration involves suppressing ego while expanding listening and communication skills. One of the most challenging aspects of a single outcome oriented studio is working from many design ideas to one solution. The structure of a team based studio is a key part of our pedagogy yet runs counter to the traditional architecture studio experience. The other reality that students come to terms with in working on a community-based project is the limit of design. Often the solution to a problem our partner has cannot be solved by design, or at best design is part of a multi-disciplinary solution. Several of our project teams have included business and law students, strategic planning consultants, farmers, engineers, web designers, artists, and an array of other consultants who together build capacity and position a project for success.

$>$ Design Excellence and Community Engagement are not mutually exclusive

Often in projects involving participatory practices Architecture is perceived as a passive vehicle for community desires where collaboration results in mediocrity. We believe in the value of design excellence, and are proving that design innovation and robust engagement can combine to produce outcomes which are useful, beautiful, empowering, and greater than the sum of their parts. Our projects have won a number of local, regional, and national design awards and show that design excellence and community engagement are not mutually exclusive. We believe this success involves focusing design not only on the project, but seeing the process of design and engagement as a design challenge as well.

\section{> Design Locally, Think Globally}

We believe in a deep commitment to place. After our city flooded in 2005 a parade of well meaning architects, urban planners, and design students came through town offering charrettes and renderings but few tangible outcomes for those who attended their meetings and gave input. As a result, many New Orleanians grew to distrust outside experts and became weary of giving their time to such exercises ${ }^{18}$. To gain the trust of our partners we have to understand the nuances of place and personalities, produce visible outcomes even if it's just a community notice board, and we have to be there to receive the call to fix a roof that is leaking, attend a pho fundraiser, or be part of a neighborhood celebration ${ }^{19}$. That is not to say a designer can't work beyond their own community, but we have found the greatest success in working locally and using those local projects as a chance to explore more global ideas and solutions and share that research with peer organizations and practitioners in other communities.

\section{CONCLUSION}

All citizens are impacted by our built environment and should be empowered to participate in the decisions that shape it. The under-served communities we work with have been historically excluded from these conversations yet hold important knowledge of the assets, opportunities, and local histories that bolster the effectiveness of a project. The work of university-based public interest design centers like ours offer new ideas on how to rethink design education, the design process, and broaden that process to include more voices and create more equitable and positive impacts for communities. While this work is happening primarily in university settings there are more career tracks and opportunities in participatory design being pioneered by practices and non-profits such as $B C$ Workshop, Center for Urban Pedagogy (CUP), GO Collaborative, and Studio $\mathrm{O}$.

Engaged design processes involves a great deal of energy, commitment to collaboration, and communication to execute well. In our city we have seen these projects give Architecture more relevance as a profession and in aggregation we believe these projects and processes can lead to more just and equitable communities. 


\section{ENDNOTES}

1 For definitions of Equity and Public Interest Design terminology used in this paper see: Christine Gaspar and Liz Ogbu, "Language, Design for Equity" Blog Posts. accessed March 15, 2017, http://www.designforequity.org/blog htm

2 Henry Sanoff, Community Participation Methods in Design and Planning. (New York: Wiley, 2000)

3 Mary C Comerio, “Community Design: Idealism and Entrepreneurship" Journa of Architecture Planning and Research 1 (1984): 227-243.

4 'Community design directory, 2014'. Association of Collegiate Schools of Architecture." Accessed August 29, 2017, http://www.acsa-arch.org/resources/ data-resources/community-design

5 "Community design centers attempt to alter ways of seeing and working. This has led to the label that design centers are alternative practices... They are not alternative work; they alter how we work. Design centers complete the work of a viable and valuable profession in the society, which as Stephen Vogel shows is a desire of a professional that the realities of traditional everyday practice prevent from becoming a priority. Design centers offer a model to fulfill this desire to expand our influence on society. Design centers have existed for less than 50 years, making them still a work in process, yet even this short history provides an opening to a broader discussion." Dan Pitera, "Amplifying the Diminished Voice' Syncopating the Urban Landscape; More People, More Programs More Geographies'. Detroit Collaborative Design Center, April 2014

6 "Conventional architectural practice depends upon clients to pay for needed professional services, thus limiting the architect's obligation to address public needs un-met by the private market. Much of the work of public interest design practices is to figure out ways to serve people who cannot afford the services of our profession and to address systemic problems in the built environment that create the needs in the first place. In other words, the transformation of architectural practice to a more public interest model can be seen as a widespread response to the nagging concern that the conventional model of practice responds solely to the paying client, thus limiting the profession's capacity to address the problems of our time." Roberta M Feldman, Sergio Palleroni, David Perkes, and Bryan Bell, Wisdom from the Field: Public Interest Architecture in Practice: A Guide to Public Interest Practices in Architecture., 2011 Latrobe Prize Report; AlA College of Fellows.

7 In speaking of the work of Rural Studio, founder Sam Mockbee was clearly placing the program in the proactive social justice territory of earlier community design projects and programs by stating, "The practice of architecture not only requires the active individual participation in the profession, but it also requires active civic engagement. The architect's primary emotional connection should always be with place, and not just the superficial qualities of place, but the ethical responsibility of shaping the environment, of breaking up social complacency and energizing one's community." Samuel Mockbee, "The Role of the Citizen Architect; transcribed remarks from Structures for Inclusion", Princeton University, 2000. Published in Good Deeds Good Design; Community Service Through Architecture. Bryan Bell, ed. (2004, p155)

8 Wicked Problems: a term from H Rittel and M Webber, "Dilemmas in a Genera Theory of Planning" In DMG Journal, 8:31-39 (1974) to describe complex social problems that have no easy solutions and often require value judgements for which they argue it is important to have involvement and dialogue amongst stakeholders. (Comerio, "Community Design").

9 The SEED network (https://seednetwork.org) has set up a framework for evaluating the Social, Economic, and Environmental, impact of Design work which many PID practitioners use as a tool for their own projects and provides a network of professionals and an array of commendable examples of other projects from which to draw lessons and best practices.

10 This is our response to a lingering issue in some 'community design' projects is something that Peattie called out in the 60's in describing how the early days of CDC projects worked, "The result was that the issues were often defined by the planners themselves, and the community groups sometimes looked upon the advocates as manipulators rather than defenders of their interests" LR Peattie, "Reflections on Advocacy Planning," American Institute of Planning Journal. 34:80-88. (1968)

11 The traditional architect-client relationship involves a transaction of services for money. From the start of a project there is an imbalance in the relationship with our partner since we raise 3rd party funding to support our work which is then offered at no expense to the partner organization. We work against this to ensure that our process and relationship is one of equals in collaboration and that our students are getting an authentic education experience As defined by Paulo Freire: "Authentic help means that all who are involved help each other mutually, growing together in common effort to understand the reality which they seek to transform. Only through such praxis -in which those who help and those who are being helped help each other simultaneously - can the act of helping become free from the distortion in which the helper dominates the helped" Paolo Freire, Pedagogy of the Oppressed, 20th anniversary ed. (New York: Continuum 1996), 1

12 Many in the PID realm rely on similar processes for engagement and have been working to refine and share these models with others. More about our process can be found in M Hansen, ET Welty, S Mobley, 'Designers, Citizens, and Citizen-Designers; Charting New Modes of Engagement, Collaboration, and Project Outcomes at Tulane City Center', ACSA National Conference Proceedings, Shaping New Knowledges, 2016.

13 For and interesting account of methods of representation and the power dynamics at play from the viewpoint of an anthropologist see Lisa Peattie, "Representation," in Planning: Rethinking Ciudad Guayana, (Ann Arbor: University of Michigan Press. 1987), 111-152.

14 Samuel Mockbee, "'The Rural Studio," in The Everyday and Architecture, AD by Jeremy Till and Sarah Wigglesworth, July/August, 1998.

15 Center for Urban Pedagogy and Liz Ogbu, "Dick and Rick; a Graphic Primer for Social Impact Design": http://welcometocup.org/file_columns/0000/0789/ dick_rick.pdf

16 "One of the curious qualities of design proactive is that it creates objects and environments out of a community process... this runs counter to the public perception of the designer as lone genius, and image that might apply to many in the fine arts, but that definitely does not fit design. Also, while design demands a high degree of creativity, the ability to see something that doesn't yet exist, it also requires good communication skills and the ability to cooperate with a wide range of other people: traits that truly make the difference between successful designers and those with little work and a lot of litigation." Thomas Fisher, Architectural Design and Ethics; Tools for Survival (Routledge, 2008), 199.

17 An article that begins to describe this process in design-build studios is: Keith and Marie Zawistowski, "Reality Check: Pedagogy at the Intersection of Practice, Education and Outreach," ACSA Working Out; Thinking While Building Fall Conference Paper Proceedings, 2014

18 For a more in-depth explaination of post-Katrina design dynamics in New Orleans: Carey Clouse and Zachary Lamb, "Post-Crisis: Embracing Public Service Architecture with Humility." Journal of Architectural Education. 67:2. (2013), 186-194.

19 Some of these lessons we are re-learning. CDC's in the 1970's ere talking about the same lessons then: "Community designers came to realize that at the local level, where they have a stake in the same issues as the groups they serve, they could really be effective. They were better able to understand the politics, the problems, and the inherent contradictions in what they did, and, at the same time, they could continue to stand up for the values and ideals that had shaped community design over the past twenty years." (Comerio, "Community Design"). 